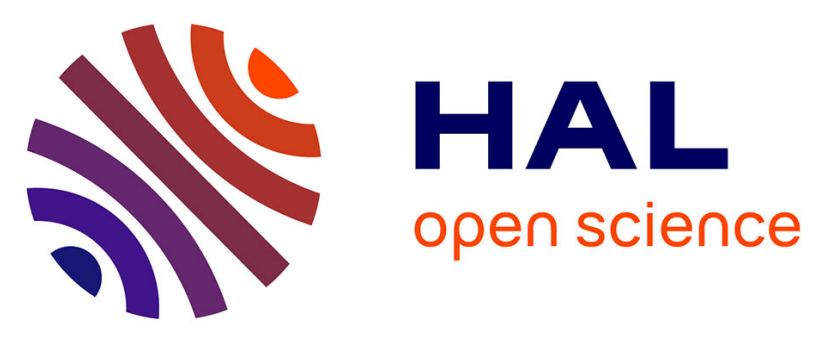

\title{
Particle Size Determination In Electrical Arcs Using X-Ray Scattering
}

\author{
Erwann Carvou, Jean-Luc Le Garrec, Elsa Yee Kin Choi, James Brian
}

Alexander Mitchell

\section{- To cite this version:}

Erwann Carvou, Jean-Luc Le Garrec, Elsa Yee Kin Choi, James Brian Alexander Mitchell. Particle Size Determination In Electrical Arcs Using X-Ray Scattering. Holm Conference on Electrical Contacts, Sep 2013, Newport, United States. pp.268-271, 10.1109/HOLM.2015.7355075 . hal-00906241

\section{HAL Id: hal-00906241 \\ https://hal.science/hal-00906241}

Submitted on 24 Jan 2018

HAL is a multi-disciplinary open access archive for the deposit and dissemination of scientific research documents, whether they are published or not. The documents may come from teaching and research institutions in France or abroad, or from public or private research centers.
L'archive ouverte pluridisciplinaire HAL, est destinée au dépôt et à la diffusion de documents scientifiques de niveau recherche, publiés ou non, émanant des établissements d'enseignement et de recherche français ou étrangers, des laboratoires publics ou privés. 


\title{
Particle Size Determination in Electrical Arcs with Ag and $\mathrm{AgSnO}_{2}$ Electrodes using X-Ray Scattering
}

\author{
E. Carvou ${ }^{1}$, J.L. Le Garrec ${ }^{1}$, E. Yee Kin Choi $^{1}$, J.-M. Jouvard ${ }^{2}$, M. Kerkar ${ }^{3}$ and J.B.A. Mitchell ${ }^{1}$ \\ ${ }^{1}$ Institut de Physique de Rennes, UMR N 6251 du CNRS, Université de Rennes I, 35042 Rennes, France \\ ${ }^{2}$ Laboratoire Interdisciplinaire Carnot de Bourgogne, UMR 6303 CNRS-Université Bourgogne Franche-Comté, Dijon, France \\ ${ }^{3}$ Laboratoire de Mécanique, Matériaux et Energétique, Faculté des Sciences Exactes, Université A. MIRA, 06000 Béjaïa, Algérie \\ Mitchell@univ-rennes1.fr
}

\begin{abstract}
This article discusses recent synchrotron radiation based measurements of nanoparticle formation between arcing contacts. The studied material is typical in contact applications, $\mathrm{Ag}$ and $\mathrm{AgSnO}_{2}$.
\end{abstract}

\section{Keywords-arcs, nanoparticles, X-ray Scattering}

\section{INTRODUCTION}

During arcing between electrical contacts, there is a movement of material between the two electrodes that leads to degradation of the switching function, over time. This phenomenon is responsible for the erosion of electrodes.

In the case of pure silver and pseudo-alloy $\mathrm{AgSnO}_{2}$ rivets, this material transfer depends on the electrodes gap among several other parameters such as the current, the voltage, the contact geometry, etc. [1]. Several regimes of mass change are highlighted in this phenomenon: anodic erosion, the compensation phase, cathodic erosion and bilateral losses.

In order to better understand the mechanism of arc formation and the influence of the arc on the electrode material, it is useful to examine the solid material that is transferred. In an effort to further understand this phenomenon, we have used Small Angle X-Ray Scattering (SAXS) to study the size of particles formed during the arcing process. Due to the arc temperature, $\mathrm{T}>5000 \mathrm{~K}$ [2], the nanoparticles are probably formed on the periphery of the plasma where the temperature gradient allows condensation processes to occur. We have already reported our results for carbon, silver and silver-tinoxide $\left(\mathrm{AgSnO}_{2}\right)$ contacts [3-6] where we found that the size and character of the nanoparticles were a clear function of the materials. While $\mathrm{AgSnO}_{2}$ electrodes have been found to generate particles with smooth surfaces in the range of 30-40 $\mathrm{nm}$ in diameter, pure silver contacts produce aggregated particles. With carbon, the particles were much larger and had rough surfaces.

In a subsequent experimental study at the Soleil Synchrotron in Saclay, France [7], we have continued our examination of this phenomenon with a wider range of materials including silver (Ag) contacts produced by differing (proprietary) metallurgical methods, $\mathrm{AgSnO}_{2}, \mathrm{AgZnO}, \mathrm{AgC}, \mathrm{Cu}, \mathrm{Al}$, Ti and brass. The results of these measurements concerning silver based contacts are presented in this article. A fuller comparative discussion of the other materials will be presented elsewhere.

\section{EXPERIMENTAL METHOD}

\section{A. Sample synthesis}

The silver samples were fabricated using 4 different metallurgical processes. The first was casting, which involved melting silver grains and casting them directly in order to produce a wire. The three last processes involve different size of silver grains in their fabrication. One process was atomization of grains, the latter being disintegrated by a highpressure jet and a shock wave. With this method, one obtains a powder with a grain size of $45 \mu \mathrm{m}$. The two remaining processes are chemical and electrolytic methods. They allow a much smaller grain size to be obtained compared with those obtained by atomization. The chemical method involves the reduction of a silver compound by a chemical agent forming silver with very fine grain size $(5 \mu \mathrm{m})$ and a sub-product which is be eliminated. The last method was electrolysis of a silver salt, which produced a precipitate with a grain size of about $25 \mu \mathrm{m}$. This is summarized in Table 1.

Table I. Grains size as a function of silver samples production method
\begin{tabular}{|c|c|}
\hline Metallurgical method & Ag grain size \\
\hline Atomization & $45 \mu \mathrm{m}$ \\
\hline Chemical & $5 \mu \mathrm{m}$ \\
\hline Electrolytic & $25 \mu \mathrm{m}$ \\
\hline
\end{tabular}

Concerning $\mathrm{AgSnO}_{2}$, the metallurgical process was atomization of $\mathrm{Ag}(45 \mu \mathrm{m})$ and $\mathrm{SnO}_{2}(4 \mu \mathrm{m})$ grains. Two different percentages by weight of $\mathrm{SnO}_{2}$ were used in this study: $3.3 \%$ and $14 \%$

\section{B. Apparatus}

The present experiment was performed on the SWING beamline of the Soleil synchrotron [5] dedicated to the SAXS technique.

The experimental apparatus (fig. 1) is a fully automated device, described in previous papers [3-5]. The apparatus is 
mainly composed of an electrical part (power supply, variable resistance) and a mechanical part using a stepping motor coupled with a sliding plate, which ensures a controlled separation between the fixed and the moving contact. A digital oscilloscope is used to sample and store the voltage and current characteristics of the arc during the break, i.e. $\mathrm{V}_{\mathrm{a}}(\mathrm{t})$ and $I_{a}(t)$. The whole system (power supply, motor and oscilloscope) is computer controlled.

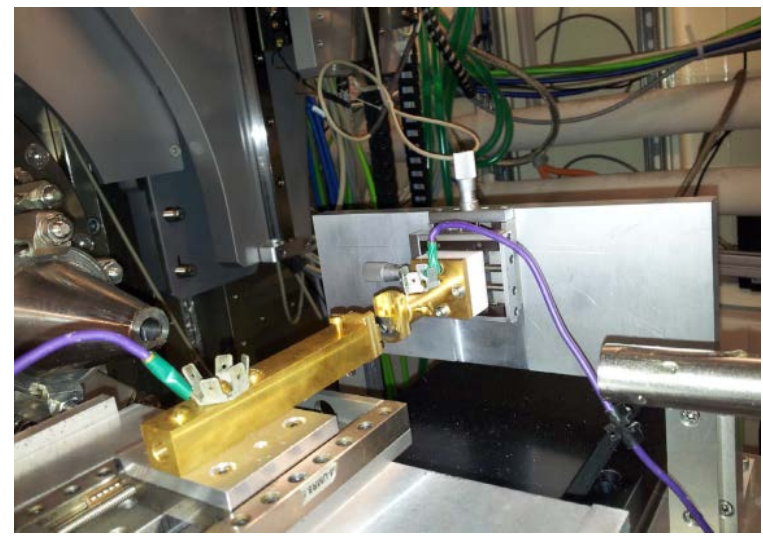

Fig. 1: Photo of the experimental apparatus mounted on the Swing beamline at the Soleil synchrotron in Saclay, France. X-rays exit the beamline through the tube on the right, pass through the inter-electrode gap (through the arc when it is lit) and enter the detector chamber through the cone on the left. The detector is located inside a 10 meter long evacuated chamber (left in the picture) and set at $4.075 \mathrm{~m}$ from the arc center.

The contacts used in the present experiment were made from commercial (Metalor Corporation [8]) silver (Ag) and $\mathrm{AgSnO}_{2}$ materials. The moving electrode had a spherical shape of 4 $\mathrm{mm}$ diameter while the fixed electrode was flat.

This apparatus performs contact breaking under initial direct current supply conditions of $400 \mathrm{~V}$ and $8 \mathrm{~A}$. This voltage/current pair was chosen in order to maintain a stable arc with a large electrode gap of $2 \mathrm{~mm}$ during the X-ray exposure. In these experimental conditions, the material transfer mode corresponds to the bilateral one. The arc begins at $\mathrm{t}=0$ when the electrodes begin to separate, with a voltage between the electrodes, initially of $12 \mathrm{~V}$ (a typical value for metallic electrode arcs maintained by the resistance of the plasma), then rising to a constant level of $25 \mathrm{~V}$, as the electrodes reach a fixed separation of $2 \mathrm{~mm}$ in less than 0.5 second. The current decreases during this time. The mean arc duration during the various measurements was $5 \mathrm{~s}$. The arc extinguishes (indicated by the sudden rise in voltage, sharp drop in current) when the power supply is switched off, followed by a more gradual fall-off of the voltage to zero volts (fig. 2).

\section{Small Angle X-Ray scattering}

As soon as the $2 \mathrm{~mm}$ gap is reached, the intense beam of $\mathrm{X}$ rays $(12 \mathrm{keV}, \lambda \approx 1 \AA$ ) from the Soleil synchrotron, passes through the arc established between the electrodes (and thus through the arc) before entering an evacuated detector chamber where they are collected and measured by a 2-D detector [7], so that their scattering pattern can be determined.

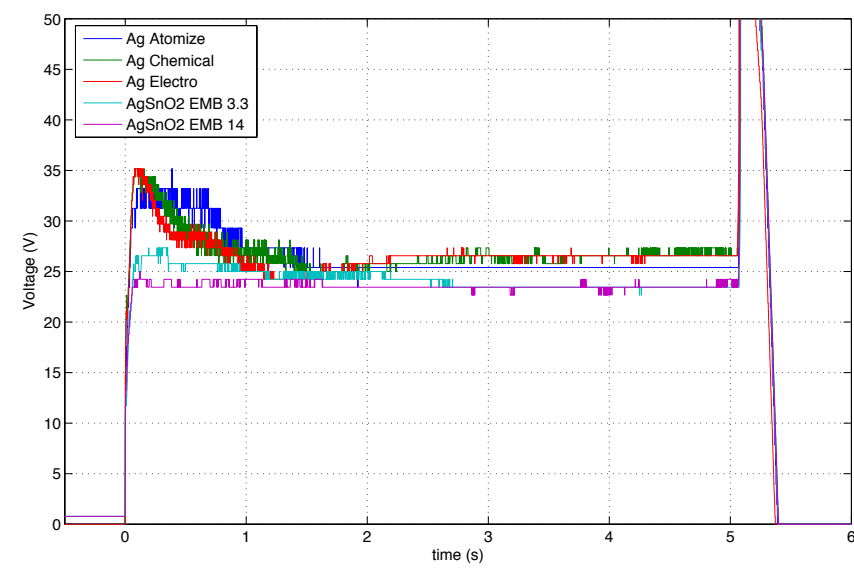

Fig 2: Arc Voltage during time for analysed materials.

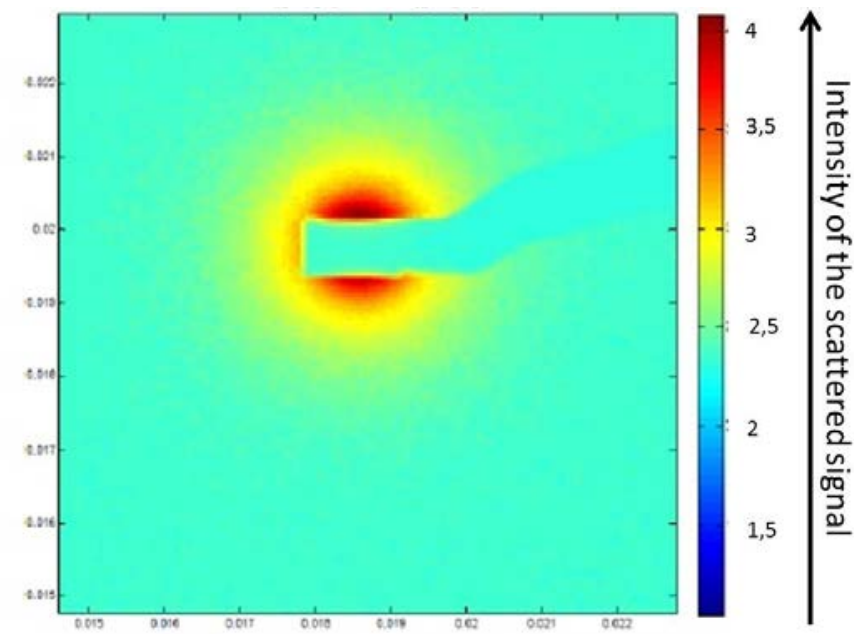

Fig. 3: Image of scattering signal as measured on the 2-D x-ray detector. The color indicates the intensity of the $x$ ray scattered beam.

A typical scattering pattern is shown in figure 3 for $\mathrm{Ag}$ contacts. The symmetric scattering patterns are integrated radially to produce graphs of Scattering Intensity (I) as a function of the momentum transfer $q=(2 \pi / \lambda) \sin (\theta / 2)$ where $\theta$ is the scattering angle with respect to the primary beam direction and $\lambda$ is the wavelength of the x-rays (see figure 4). The distance between the arc center and the detector in these experiments was held fixed at $4.075 \mathrm{~m}$ which allows measurements made over a q range from $0.003-0.27 \AA$.

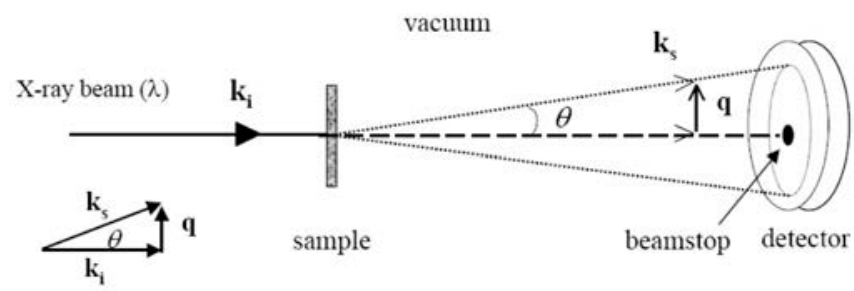

Figure 4 Schematic layout of a SAXS setup (from ref. [9]). 
One can make an approximation for the size of the particles [10] using the expression $\mathrm{D} \approx \pi / \mathrm{q}$ and so the particle size range that we could examine lay between $1.2 \mathrm{~nm}$ and $100 \mathrm{~nm}$. A series of measurements are taken in series with exposure times of $250 \mathrm{~ms}$ separated by a deadtime (for data readout) of $250 \mathrm{~ms}$. During this series, the arc is lit and then extinguishes when the voltage on the contacts is cut off. By subtracting the measurement without arcing at the end of the sequence from those with arc present, the influence of background air scattering and thermal effects can be eliminated.

\section{RESULTS AND DISCUSSION}

For isolated particles, such as nanoparticles in the gas phase, the scattering from a given structural level is described by a Guinier's law and a structurally limited power law, I(q) $\propto \mathrm{q}^{-\mathrm{p}}$, depicting a Porod region. The power law exponent, $p$, gives information on the morphology of the particulate system. For instance, $p=4$ signifies a sharp interface between the particle and its surrounding medium whereas $p=2$ is related to a Gaussian polymer chain [11]. The Porod region is observed at large q (i.e. large angles) where the scattered intensity is proportional to the surface area per unit volume. The Guinier law is described by [10]:

$$
I(q)=I_{0} \exp \left(-\frac{q^{2} R_{g}^{2}}{3}\right)
$$

where $I_{0}$ is the scattered intensity not related to the shape of the particle and $R_{g}$ is the radius of gyration. This law is valid only for small angles, i.e. $\mathrm{qR}_{\mathrm{g}}<<1$ and provides information on both the radius of gyration of the scattering particles and the target number density. Therefore, on a log-log plot, the scattered intensity is reflected by a knee at low q (Guinier region) and a linear region at higher $\mathrm{q}$ (Porod region).

Figure 5 shows I vs q diagrams for $\mathrm{Ag}$ and $\mathrm{AgSnO}_{2}$ contacts and it is seen that their scattering behavior is quite different in the Guinier region (low q) though very similar in the high $q$ (Porod) region. At large $\mathrm{q}$, the slope of the curve (i.e. Porod exponent $p$ ) in these experiments was found to be systematically $\mathrm{q}^{-4}$ which indicates so-called Porod scattering which means that the interface between the particle surface and the surrounding air is smooth. In essence this implies that the particles are spherical.

The data was collected, processed and analyzed using the inhouse software on the Swing beamline (Foxtrot -3.036-3Swing).

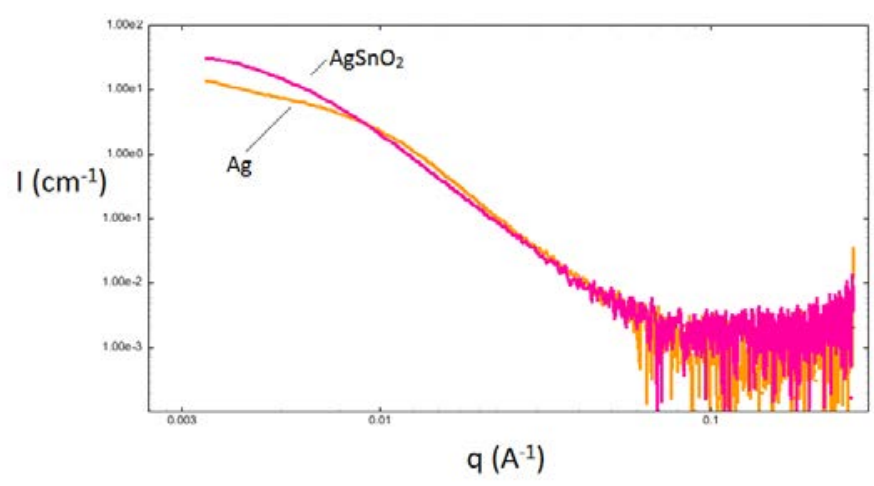

Fig. 5: Intensity vs q plots for pure silver (Ag) contacts (orange) and $\mathrm{AgSnO}_{2}$ contacts (Red). It should be noted that the Guinier region for the Ag contacts occurs at much higher $q$ (around $10^{-2} \mathrm{~A}^{-1}$ ) than for the $\mathrm{AgSnO} \mathrm{O}_{2}$ contacts (around 0,006 $10^{-3} \mathrm{~A}^{-1}$ ) indicating the particles are smaller in the Ag case.

Table 2 Radius of gyration of nanoparticles formed in electrical arcs according to the base material and preparation method.

\begin{tabular}{|c|c|c|}
\hline Base Material & Preparation Method & $\mathrm{Rg}(\mathrm{nm})$ \\
\hline $\mathrm{Ag}$ & Casted & $24-26$ \\
\hline $\mathrm{Ag}$ & Atomized & 18.5 \\
\hline $\mathrm{Ag}$ & Chemical & $17-19$ \\
\hline $\mathrm{Ag}$ & Electrolytic & $17.5-19.5$ \\
\hline $\mathrm{AgSnO}$ & $3.3 \% \mathrm{SnO}_{2}$ & $30-45$ \\
\hline $\mathrm{AgSnO}_{2}$ & $14 \% \mathrm{SnO}_{2}$ & $35-38$ \\
\hline
\end{tabular}

It can be seen directly from figure 4 that the particles formed with silver $(\mathrm{Ag})$ contacts are smaller than those formed by $\mathrm{AgSnO}_{2}$ contacts. In fact in these experiments, silver produced by different methods was used and two different $\mathrm{AgSnO}_{2}$ samples had $3.3 \%$ and $14 \%$ respectively of $\mathrm{SnO}_{2}$. The results for these different materials are listed in table I.

\section{CONCLUSION}

The results found here confirm our earlier studies which were mainly concentrated on $\mathrm{AgSnO}_{2}$, namely that the particles sizes were in the $30-40 \mathrm{~nm}$ range and that they exhibited smooth surfaces. Furthermore, in the case of pure silver contacts, the particle sizes are generally considerably smaller though there seems to be some variation depending upon the fabrication methods for the actual contacts, with pure silver yielding larger particles than those formed using powder and chemical based methods.

\section{ACKNOWLEDGMENT}

The authors wish to thank Synchrotron SOLEIL for financial and technical support of these measurements, performed on the SWING beamline. Thanks are also due to Metalor Corporation for supplying the electrode materials. 


\section{REFERENCES}

[1] E. Yee Kin Choi, E. Carvou, C. Bourda, A. Vassa, N. Ben Jemaa, and J.B.A. Mitchell, Optimization of material erosion and welding performance by metal oxides and magnetic particles, ICEC2014, Dresden, pp.61-66

[2] P.G. Slade, Electrical Contacts: Principles and applications, CRC Press Taylor \& Francis Group edition, New York, 2014

[3] E. Carvou et al. IEEE Transactions on Plasma Science, 41, 3151 (2013)

[4] E. Carvou, J.L. LeGarrec, E. Yee Kin Choi and J.B.A Mitchell, Particle size determination in electrical arcs using $X$-ray scattering, Proc. IEEE Holm Conf. EC, Oct. 2013, pp.268-271

[5] E. Carvou et al. AIP Advances 3, 032139 (2013)
[6] E. Carvou et al. 27th Int. Conf. Elec. Contacts (ICEC), VDE Verlag GMBH, Berlin, p. 680.

[7] http://www.synchrotronsoleil.fr/Recherche/LignesLumiere/SWING

[8] http://www.metalor.com/fr/electrotechnics/Products/Silve r-alloys/AgSnO2

[9] T. Narayanan. Synchroton small-angle x-ray scattering. In R. Borsali and R. Pecora, editors, Soft-Matter Characterization XXXVI, page 899, 2008.

[10] A. Guinier, X-ray Diffraction in crystals, Imperfect Crystals and Amorphous Bodies, New york, USA Dover 1994

[11] P.W. Schmidt. In H. Brumberger (ed.), Modern Aspects of Small Angle Scattering. Kluwer Academic, Dordrecht, page 1,1995 